\title{
Practical aspects regarding the histopathological grading and anaplastic transformation of gangliogliomas - a literature review
}

\author{
ANTONia CARMEN LISIEVICI ${ }^{1}$, MiHAI GHEORGHe LISIEVICI ${ }^{2)}$, DiANA PAŞOV ${ }^{2}$, \\ TIBERIU Augustin GEORGESCU ${ }^{1,3)}$, OCTAVIAN MUNTEANU ${ }^{4,5)}$, CORINA GRIGORIU ${ }^{4,6)}$, \\ ROXANA ELENA BOHÎLTEA ${ }^{4,6)}$, FLORENTINA Ligia FuRTUNESCU 7 , MARIA SAJIN ${ }^{1,8)}$ \\ 1) Discipline of Pathology, Carol Davila University of Medicine and Pharmacy, Bucharest, Romania \\ 2) Department of Pathology, Bagdasar-Arseni Emergency Clinical Hospital, Bucharest, Romania \\ ${ }^{3)}$ Department of Pathology, Alessandrescu-Rusescu National Institute for Mother and Child Health, Bucharest, Romania \\ 4) Discipline of Obstetrics and Gynecology, Carol Davila University of Medicine and Pharmacy, Bucharest, Romania \\ 5) Discipline of Anatomy, Carol Davila University of Medicine and Pharmacy, Bucharest, Romania \\ 6) Department of Obstetrics and Gynecology, Emergency University Hospital, Bucharest, Romania \\ 7) Department of Public Health and Management, Faculty of Medicine, Carol Davila University of Medicine and Pharmacy, \\ Bucharest, Romania \\ 8) Department of Pathology, Emergency University Hospital, Bucharest, Romania
}

\begin{abstract}
Ganglioglioma represents a benign central nervous tumor, occurring predominantly in the pediatric population and affecting the temporal lobe. It is also renowned for its epileptogenic potential. However, to date, there are numerous uncertain features about this tumor, especially about its grading system. In the former World Health Organization (WHO) Classification of central nervous tumors system, gangliogliomas could have been attributed one out of three grades: grade I (benign), grade II (atypical), and grade III (anaplastic). The new classification systems have renounced to atypical ganglioglioma nomenclature, due to the lack of histopathological criteria for this entity. Another controversial aspect of grade I ganglioglioma is its potential to transform into a malignant tumor, namely, most frequently an anaplastic ganglioglioma. Based on our knowledge, there are no literature reviews to date focusing on anaplastic transformation potential. The present paper encompasses all anaplastic transformation of gangliogliomas and has analyzed the time frame between the two events, the age of the patients and its relationship to the complete or subtotal resection and administration of radiotherapy. Thirty-three cases of malignant transformation of ganglioglioma have been reported so far in the literature, with $54.54 \%$ of them undergoing progression to anaplastic ganglioglioma and $21.21 \%$ to anaplastic ganglioglioma. Median age was 26 years, and the cases were evenly distributed between the two genres. Only $27.27 \%$ of all evaluated cases had been administrated adjuvant radiotherapy, and only $44 \%$ of the latter have had an incomplete tumoral resection.
\end{abstract}

Keywords: ganglioglioma, anaplastic transformation, grading ganglioglioma.

\section{Introduction}

Although ganglioglioma is an extremely rare tumor, it is, nonetheless, one of the most common tumors arising in the pediatric population. They are well-differentiated, slowly growing, mixed tumors, often arising in the temporal lobe, in patients with epileptic seizures [1]. Histopathologically, it is made of two intertwining populations: one consisting of dysplastic neurons and one consisting of neoplastic astroglial cells. On the other hand, anaplastic ganglioglioma [World Health Organization (WHO) grade III] tends to occur in adults or elderly patients, do not usually arise in the temporal lobe and have increased cellularity and proliferation of the glial component $[2,3]$. Classical features suggesting malignancy, like necrosis and microvascular proliferation, can also be encountered.

To this day, little is known about the histopathological (HP) grading of ganglioglioma, although many case reports, studies, and reviews, were conducted separately, regarding either gangliogliomas or anaplastic gangliogliomas. While the $W H O$ Classification has suffered great changes along the past years, the general acceptance of this grouping remains low, due to the lack of consensus and, more importantly, lack of details concerning the HP features of this split. Although it is clear that most tumors can easily be classified as either benign or malignant, there are also rare cases which do not meet either criteria. Therefore, the question remains: should we upgrade them to the anaplastic category and risk overtreatment, or should we put them into the benign category and hope that the follow-up will reveal no tumor progression? Perhaps further studies with thorough correlation between HP features and clinical outcome will eventually lead to the development a softwarebased scoring system to stratify therapeutic management, as it happened with some pathologies of other organs and systems [4].

This is an open-access article distributed under the terms of a Creative Commons Attribution-NonCommercial-ShareAlike 4.0 International Public License, which permits unrestricted use, adaptation, distribution and reproduction in any medium, non-commercially, provided the new creations are licensed under identical terms as the original work and the original work is properly cited. 


\section{a Materials and Methods}

A thorough search on PubMed, Medline and Google using various combinations of the following headings: "ganglioglioma", "anaplastic transformation", and "grading gangliogliomas" revealed a total of 33 cases published in the English literature since 1962, mainly as isolated case reports or short case series.

\section{ㅁ Results}

Table 1 summarizes the main characteristics of the 33 patients with grade I gangliogliomas reported to have suffered anaplastic transformation.
Analyzing the data retrieved from the above-mentioned studies, we quickly observe that most cases underwent malignant transformation into anaplastic ganglioglioma (54.54\%), while only $21.21 \%$ of patients suffered an upgrade of the HP aspects, leading to glioblastomas. Only a minority featured either malignant transformation of both neuronal and glial components $(6.06 \%)$ or underwent transformation into an anaplastic astrocytoma $(6.06 \%)$ or neuroblastoma (6.06\%). Exceptional case reports have described malignant transformation of grade I gangliogliomas into gliosarcoma [26] and a primitive neuroectodermal tumor (PNET) [21].

Table 1 - Cases of malignant transformation in ganglioglioma reported in the scientific literature

\begin{tabular}{|c|c|c|c|c|c|c|c|}
\hline $\begin{array}{l}\text { Case } \\
\text { No. }\end{array}$ & $\begin{array}{l}\text { Authors (year) } \\
\text { [Ref. No.] }\end{array}$ & $\begin{array}{c}\text { Age } \\
\text { [years] }\end{array}$ & Gender & $\begin{array}{l}\text { Complete } \\
\text { resection }\end{array}$ & $\begin{array}{c}\text { Age of malignant } \\
\text { transformation } \\
\text { [years] }\end{array}$ & $\begin{array}{l}\text { Radiotherapy } \\
\text { treatment }\end{array}$ & $\begin{array}{l}\text { Histological variant of the } \\
\text { malignant transformation }\end{array}$ \\
\hline 1. & $\begin{array}{c}\text { Rusell \& Rubinstein (1962) } \\
{[5]}\end{array}$ & NA & M & NA & +23 & Yes & Glioblastoma \\
\hline 2. & $\begin{array}{c}\text { Kalyan-Raman \& Olivero } \\
(1987)[6]\end{array}$ & NA & NA & Yes & +5 & Yes & Glioblastoma \\
\hline 3. & Jay et al. (1994) [7] & 10 & M & No & 13 & Yes & $\begin{array}{l}\text { Malignant transformation of } \\
\text { both tumoral components } \\
\text { (neuronal and glial) }\end{array}$ \\
\hline 4. & Sasaki et al. (1996) [8] & 26 & $\mathrm{M}$ & Yes & 32 & No & Anaplastic ganglioglioma \\
\hline 5. & Kurian et al. (1998) [9] & 10 & $\mathrm{~F}$ & Yes & 11 & No & Anaplastic ganglioglioma \\
\hline 6. & \multirow{4}{*}{$\begin{array}{c}\text { Rumana \& Valadka (1998) } \\
{[10]}\end{array}$} & 32 & $\mathrm{~F}$ & Yes & 34 & Yes & Anaplastic astrocytoma \\
\hline 7. & & 24 & $\mathrm{M}$ & No & 36 & Yes & Anaplastic ganglioglioma \\
\hline 8. & & 56 & $\mathrm{M}$ & No & 60 & Yes & Anaplastic astrocytoma \\
\hline 9. & & 30 & M & Yes & 34 & Yes & Glioblastoma \\
\hline 10. & Mittler et al. (1999) [11] & 4 & NA & Yes & 21 & No & Glioblastoma \\
\hline 11. & David et al. (2000) [12] & 18 & $\mathrm{~F}$ & Yes & 25 & No & Neuroblastoma \\
\hline 12. & Hayashi et al. (2001) [13] & 16 & $\mathrm{~F}$ & No & 25 & No & Glioblastoma \\
\hline 13. & \multirow{4}{*}{$\begin{array}{l}\text { Wharton et al. (2000) [14]; } \\
\text { Whittle et al. (2002) [15] }\end{array}$} & 39 & $\mathrm{M}$ & No & 40 & No & Anaplastic ganglioglioma \\
\hline 14. & & 34 & $\mathrm{~F}$ & No & 35 & No & Anaplastic ganglioglioma \\
\hline 15. & & 26 & $\mathrm{M}$ & No & 29 & No & Anaplastic ganglioglioma \\
\hline 16. & & 39 & M & Yes & 41 & No & Anaplastic ganglioglioma \\
\hline 17. & Tarnaris et al. (2006) [16] & 45 & $\mathrm{~F}$ & Yes & 47 & Yes & Neuroblastoma \\
\hline 18. & Mittelbronn et al. (2007) [17] & 47 & $\mathrm{~F}$ & NA & 49 & No & $\begin{array}{l}\text { Malignant transformation of } \\
\text { both tumoral components } \\
\text { (neuronal and glial) }\end{array}$ \\
\hline 19. & Majores et al. (2008) [18] & NA & NA & No & NA & No & Glioblastoma \\
\hline 20. & Reis et al. (2012) [19] & 9 & $\mathrm{M}$ & No & 13 & No & Glioblastoma \\
\hline 21. & \multirow{2}{*}{ Lee et al. (2012) [20] } & 56 & $\mathrm{M}$ & Yes & 57 & No & Anaplastic ganglioglioma \\
\hline 22. & & 61 & $\mathrm{~F}$ & No & 61 & No & Anaplastic ganglioglioma \\
\hline 23. & Bendersky et al. (2012) [21] & 19 & $\mathrm{M}$ & Yes & 22 & No & PNET \\
\hline 24. & Morana et al. (2013) [22] & 2 & $\mathrm{~F}$ & No & 9 & No & Anaplastic ganglioglioma \\
\hline 25. & \multirow{3}{*}{ Zanello et al. (2016) [23] } & 7 & $M$ & No & 10 & No & Anaplastic ganglioglioma \\
\hline 26. & & 16 & $\mathrm{~F}$ & No & 16 & No & $\begin{array}{c}\text { Anaplastic ganglioglioma with } \\
B R A F(V 600 E) \text { and } H 3 F 3 A \\
(p . K 27 M) \text { mutations }\end{array}$ \\
\hline 27. & & 8 & $\mathrm{~F}$ & Yes & 11 & No & $\begin{array}{c}\text { Anaplastic ganglioglioma with } \\
\text { BRAF V600E mutation }\end{array}$ \\
\hline 28. & \multirow{2}{*}{ Joyon et al. (2017) [24] } & 12 & $\mathrm{~F}$ & NA & 19 & No & Anaplastic ganglioglioma \\
\hline 29. & & 25 & M & NA & 25 & No & Anaplastic ganglioglioma \\
\hline 30. & Lummus et al. (2014) [25] & 27 & $\mathrm{~F}$ & No & 32 & Yes & Anaplastic ganglioglioma \\
\hline 31. & Qiu et al. (2017) [26] & 59 & $\mathrm{~F}$ & No & 62 & No & Gliosarcoma \\
\hline 32. & Rosselló et al. (2017) [27] & 43 & $\mathrm{~F}$ & No & 46 & No & Anaplastic ganglioglioma \\
\hline 33. & Riesberg et al. (2018) [28] & 13 & $\mathrm{M}$ & Yes & 20 & No & Anaplastic ganglioglioma \\
\hline
\end{tabular}

BRAF: B-Raf proto-oncogene, serine/threonine kinase; F: Female; H3F3A: H3 histone, family 3A; M: Male; NA: Not available; PNET: Primitive neuroectodermal tumor. 
Patients' age varied from two to 61 years old, with an average of 28.9 years and a median of 26 years. The period of time passed between the excision of the primary tumor and the malignant transformation varied between three months and 23 years (average of 5.18 years and median of three years). Gender-wise, the cases were equally distributed between the two genders.

Regarding the controversial radiotherapy treatment [10, 16, 29], 27.27\% of patients underwent adjuvant radiotherapy with subsequent malignant transformation. Out of the cases which have received radiotherapy, only $44 \%$ of them have had an incomplete/subtotal resection of the primary tumor. No correlations were observed between the incomplete excision of the tumor and the interval between the primary tumor and the malignant transformation, in patients who underwent radiotherapy. The average time passed between the first and the second excision was six years, in patients with incomplete resection who underwent radiotherapy and $7.6 \%$ in those with total resection of tumor. Out of all reported cases, $48.48 \%$ had a subtotal resection of the first tumor, $39.39 \%$ underwent total resection of the tumor, with no imagistically detectable remaining tumor and $12.12 \%$ of the reports did not mention whether the first excision was complete or not.

\section{ㅁ Discussions}

\section{Clinical features}

Gangliogliomas usually affect children and young adults, although cases have been reported in patients with a wide age range, from eight months to 70 years [30]. Intracranial tumors are rare in pregnancy and may present a diagnostic and therapeutic challenge. However, anaplastic ganglioglioma is one of the several subtypes of aggressive malignant tumors reported during the third trimester of pregnancy $[31,32]$. They are usually located in the temporal lobe $(70 \%)$, although other anatomic areas can also be involved, especially the cerebellum, the spinal cord, the frontal lobe, the brainstem, or the pineal gland [2]. Studies show a worse prognosis for those situated in the brainstem, compared to those which have a supratentorial location, with a 3.5- to 5-fold increased risk of recurrence [33]. Patients usually present with a long history of epileptic seizures, that do not typically respond to antiepileptic medicine, especially when the tumor involves the neocortex or temporal lobe. Other uncommonly encountered symptoms range from headache, nausea, visual disturbances, and fatigue - if situated in the hypothalamus or third ventricle [34] - to progressive myelopathy, motor and sensory defects, gait abnormalities and bowel or bladder dysfunction - if situated in the spinal cord [33, 35].

Although not currently encompassed in the current WHO Classification system due to the lack of consensus regarding its HP features, many authors still believe that grade II gangliogliomas should not be totally removed from the grading system. Regarding the clinical features, they are extremely similar to those of grade I ganglioglioma, namely young adults, presenting with epileptic seizures due to a tumor located in the temporal lobe. One article even presents a case of a $W H O$ grade II ganglioglioma, which has evolved into a glioblastoma, this way questioning the apparently "intermediate" HP grade [36].

Anaplastic gangliogliomas ( $\mathrm{WHO}$ grade III) are much rarer tumors than their benign counterparts, accounting for approximately $3-5 \%$ of all gangliogliomas, and although they usually affect patients in the same age range, studies have shown a slight tendency to affect older patients, with a mean age of $35 \pm 14.5$ years $[37,38]$. They are usually supratentorial, with most tumors occurring in the temporal and parietal lobes, but rare cases occurring in the spinal cord have also been reported. Involvement of the temporal lobe is not that frequently encountered, in comparison to $W H O$ grade I gangliogliomas [37]. Symptoms are similar to those located in the same anatomic regions as the $\mathrm{WHO}$ grade I ganglioglioma [39]. Several authors state that grade III gangliogliomas may arise from the malignant transformation of grade I ganglioglioma. One case report even presents a patient where the transformation was into a combined ganglioglioma and pleomorphic xanthoastrocytoma with anaplastic features [25]. The malignant transformation was usually linked to either incomplete therapy, although some authors have claimed in the past, that radiotherapy might also play a role in this degeneration $[10,18]$. In a few case reports, malignant transformation was also accompanied by leptomeningeal spread [25, 28].

\section{Imaging aspects}

Grade I gangliogliomas (Figure 1) usually appear as a well-circumscribed, low-density enhancing mass, which may associate cystic areas and even calcifications [40] on computed tomography (CT) examination. Clues revealing the slow growing nature of the tumor, like bony remodeling or thinning can sometimes be observed. On magnetic resonance imaging (MRI), the solid component tends to be iso- to hypointense in T1, has pronounced signal increase in proton-density weighted images and less hyperintense in T2 [6]. Also, the content of the cystic mass has a higher signal in T2, than cerebrospinal fluid (CSF), correlating to the gelatinous mass, which can sometimes be found intraoperatively [41]. More than half of the cases have a perilesional edema and tumors occurring in children tend to have larger dimensions [42].

On the other hand, grade II gangliogliomas tend to look more like a true malignant neoplasm: larger dimensions, that appears to extend into the surrounding tissue, with an inhomogeneous aspect. Scant edema and little mass effect can also be observed [43]. Atypical features, like intratumoral hemorrhage or bi-hemispherical extension can occur (Figure 2).

Anaplastic ganglioglioma, although slowly growing, can have extremely aggressive features. Most of them have large dimensions, they can erode the skull and even extend beyond it, sometimes without having even any effect on the median line. They can also have positive mass effect with near complete effacement of the lateral ventricles, especially if located in the temporal lobe $[3,44]$. They present as hyperintense or isointense in T1 scans, with more pronounced edema and "ring" Gadolinium enhancement (Figures 3 and 4) [41]. 


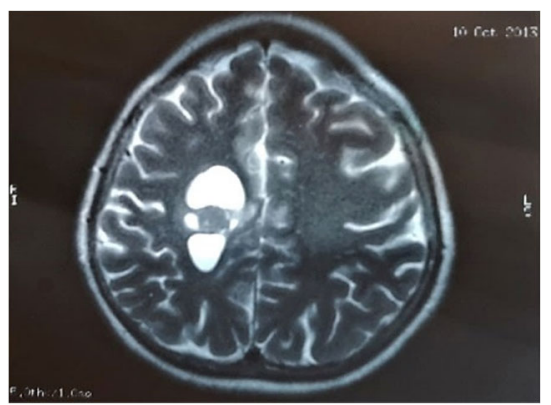

Figure 1 - Typical aspect of a grade I ganglioglioma featuring both a cystic and a solid component, affecting mostly the temporal lobe (T2-weighted MRI image). MRI: Magnetic resonance imaging.

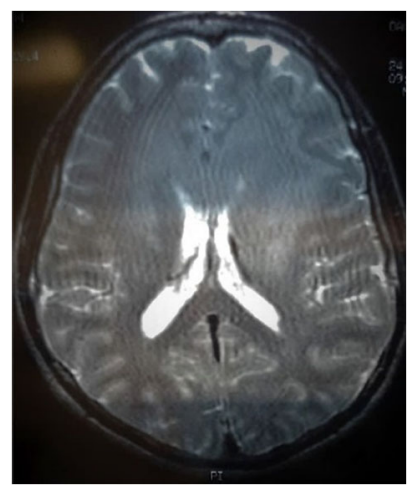

Figure 2 - Malignant ganglioglioma presenting as a diffuse mass affecting both hemispheres (frontal and temporal lobes) and discretely compressing the lateral ventricles (T2-weighted MRI image).

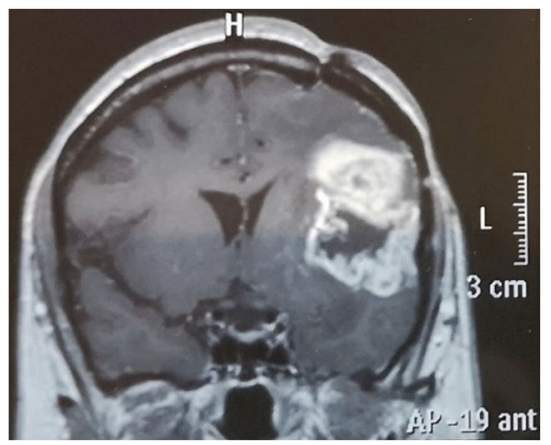

Figure 3 - Recurring ganglioglioma showing a large, irregular temporal mass with a cystic component and mural nodule featuring contrast enhancement (contrastenhanced T1-weighted MRI image).

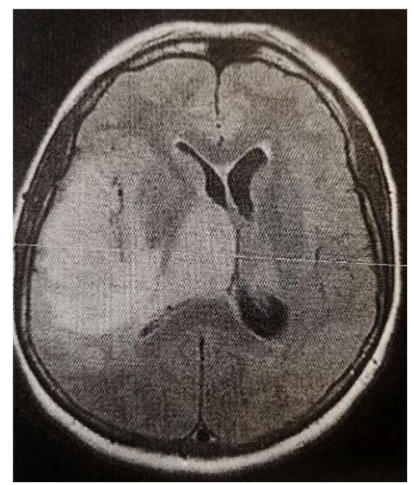

Figure 4 - Anaplastic ganglioglioma presenting as a large, irregular temporal mass, with no cystic component. The tumor is compressing the lateral ventricle (contrastenhanced T1-weighted MRI image).

\section{Practical histopathological aspects}

To establish the diagnosis of ganglioglioma, one must identify two types of cellular populations: a neuronal and a glial one, both with clearly benign features. Either one of them can predominate. The glial component can have characteristics of either pilocytic astrocytoma, fibrillary astrocytoma or even oligodendroglioma. This is the component which gives the tumor its HP grade. The glial cells usually do not cluster around the neuronal proliferation [45]. The neuronal component (Figure 5), which is organized in nests, can also have features of atypia (lack of orientation, bizarre shapes, variable sizes, vesicular nuclei, and conspicuous nucleoli) [1]. The cells can have cytomegalic features, binucleation, bizarre nuclei or even ganglioid aspects [2, 46]. A perimembranous condensation of the Nissl substance and the presence of argyrophilic processes are also frequently encountered features. This perimembranous condensation can be highlighted through the Cresyl Violet staining, and the presence of the neuronal processes is identifiable through the modified Bielschowsky, Holmes and Bodian staining.

Regarding the surrounding matrix, one can observe the presence of eosinophilic granular bodies or Rosenthal fibers (mostly accompanying the glial component), suggestive for a long-standing course of progression, and also a fibrillary matrix sustaining the proliferating cells. To illustrate the rich reticulin network, a Reticulin staining can be useful [1]. Desmoplasia (deposition of collagen in the neuropil), a rather prominent capillary network and calcifications are also features of $\mathrm{WHO}$ grade I ganglioglioma $[45,47]$. Surrounding the neoplastic proliferation is a lymphoplasmocytic infiltrate, admixed with activated microglia (Figure 6). Nonetheless, the lack of inflammatory reaction, does not exclude this diagnosis [48].

One should be aware of a diagnostic pitfall, in those exceptional cases, where the neuronal component predominates and where cortical dysplasia or gangliocytoma can be in the differential diagnosis. On the other hand, if the glial component predominates and the neuronal component is inconspicuous, one might be tempted to diagnose the lesion as an astrocytoma [1].

There is not much data concerning the HP diagnosis, or the clinical outcome of atypical ganglioglioma ( $\mathrm{WHO}$ grade II), henceforth the decision to remove this entity from the $2016 \mathrm{WHO}$ Classification. In our opinion, the most thorough and accurate paper on this theme is the retrospective study published by Luyken et al., in 2004, in which they analyze cases and evaluate their outcome for a period of eight years. In their study, the threshold for diagnosis of atypical ganglioglioma (Figure 7) was based on the presence of microvascular proliferation, increased cellularity (Figure 8), obvious nuclear pleomorphism of the glial component and increased Ki67 proliferative index (above $5 \%$ ) [49]. Other authors have considered a proliferative index of $10 \%$ as the threshold between low grade ( $\mathrm{WHO}$ grade I and II) and high grade ( $W H O$ grade III) [41]. Majores et al. also included the presence of an increased mitotic rate in their grading system [18]. On the opposite side, Blümcke $\&$ Wiestler have regarded the presence of microvascular proliferation and mitotic activity as criteria for anaplastic ganglioglioma [37]. Nevertheless, since many studies, including that of Majores et al. [18] have reported more cases of grade II ganglioglioma than anaplastic ganglioglioma, the need of this category should not be doubted. 
Regarding the anaplastic ganglioglioma ( $W H O$ grade III), most authors believe that it consists of a malignant transformation of the glial component. Studies have shown that increased cellularity, increased mitotic activity, presence of necrosis and microvascular proliferation (Figure 9) are elements that aid in making this diagnosis [2]. Mitoses are only rarely observed in the neuronal component, feature also confirmed by the Ki67\% proliferative index, which is positive only in the neoplastic astrocytes (Figure 10) [45].
In rare cases, malignant transformation of a previously incompletely resected ganglioglioma can occur [2, 37]. Lucas et al. even reported a case in which the anaplastic ganglioglioma developed on a previously resected lowgrade astrocytoma, in concordance to the hypothesis that they develop in long lasting lesions [39]. Another paper, from Bouali et al., reported seven juvenile anaplastic ganglioglioma, due to secondary malignant transformation of $W H O$ grade I ganglioglioma [50].

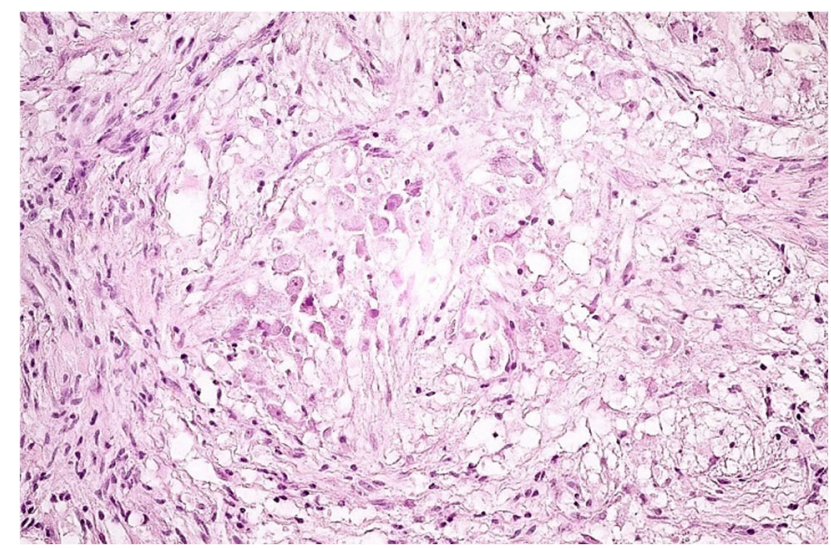

Figure 5 - Grade I ganglioglioma showing a cluster of neuronal cells dispersed in a mixture of glial cells [Hematoxylin-Eosin (HE) staining, $\times 400]$.

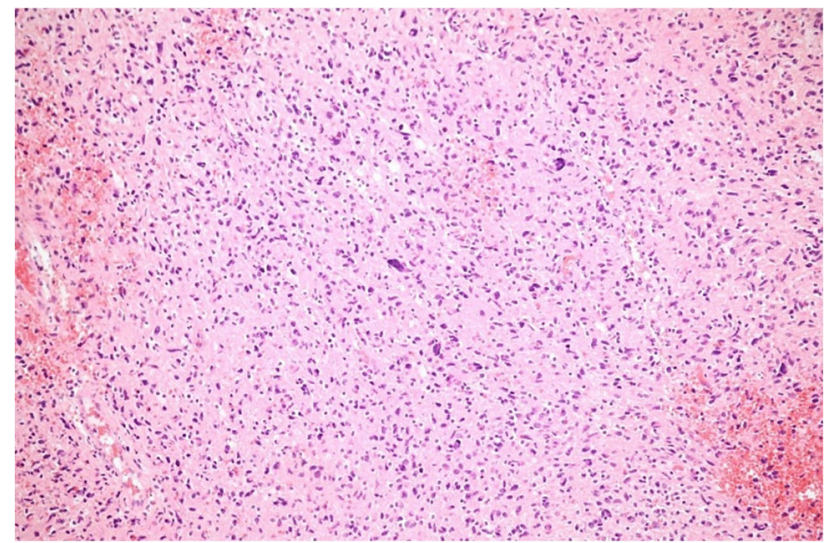

Figure 7 - Atypical ganglioglioma featuring an increased cellularity with rare intermingled dysmorphic neurons (HE staining, $\times 200$ ).

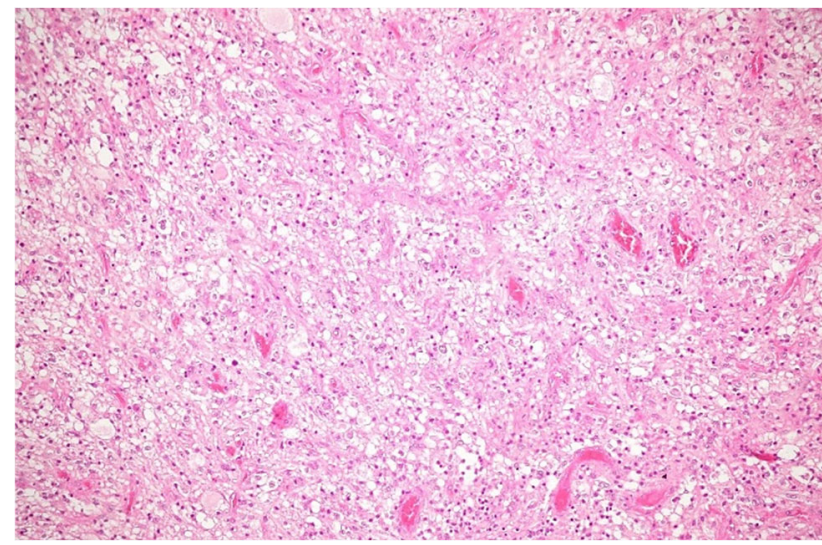

Figure 9 - Anaplastic ganglioglioma showing marked cellular pleomorphic of the glial proliferation, which encompasses rare dysmorphic neurons. Increased vascularization, suggestive for aspects of microvascular proliferation can also be observed (HE staining, $\times 200)$.

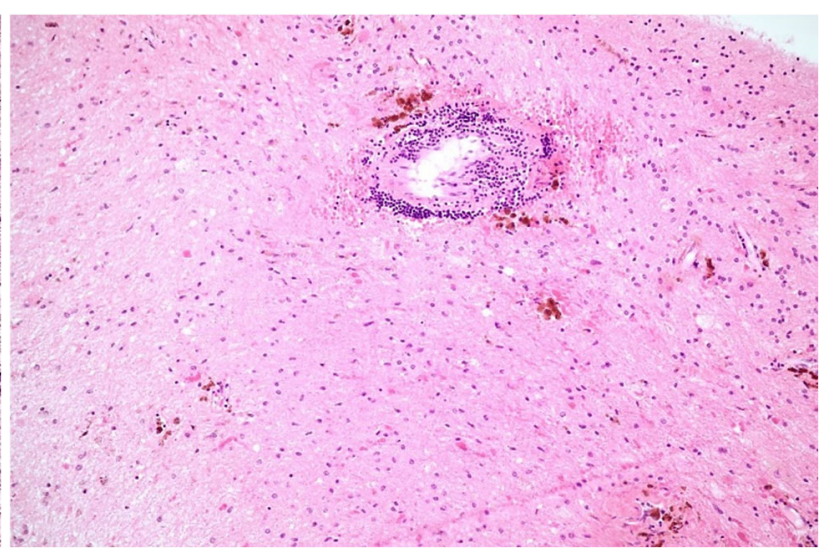

Figure 6 - Grade I ganglioglioma showing a bland glial proliferation with perivascular lymphocytic cuff, characteristic of neuronal proliferations (HE staining, $\times 200$ ).

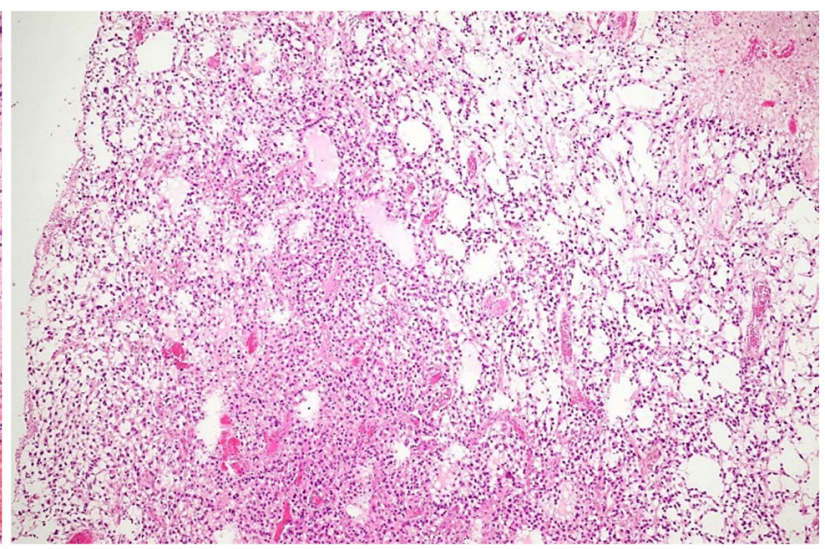

Figure 8 - Atypical ganglioglioma featuring a hypercellularity of the glial component, which has features of a pilocytic astrocytoma (HE staining, $\times 200)$.

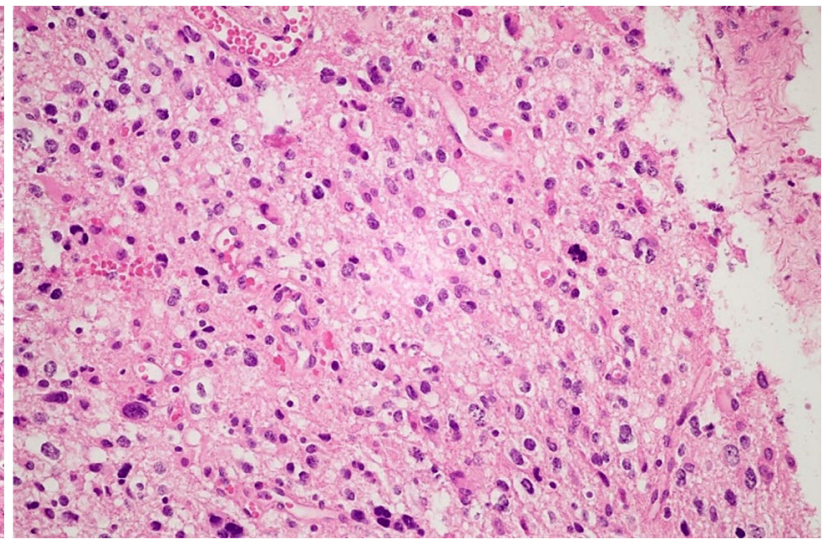

Figure 10 - High-power field of an anaplastic ganglioglioma showing marked hypercellularity, pleomorphism and atypical mitosis (HE staining, $\times 400)$. 


\section{Practical immunohistochemical aspects}

There are multiple aspects regarding the immunohistochemical approach of these neoplasms. First of all, it is necessary to confirm the presence of a mixed glioneuronal proliferation and exclude a gangliocytoma or an astrocytoma. To achieve this goal, one must demonstrate the presence of the neuronal component through microtubuleassociated protein 2 (MAP2), synaptophysin, chromogranin A, neuronal nuclei (NeuN), and neurofilaments [2, 50], respectively of the glial component through glial fibrillary acidic protein (GFAP) [2].

Second of all, once the histogenesis is established, one should try to establish the grading. Probably, Ki67 is the most useful immunomarker for this decision. It is unanimous in the literature that a low proliferative index, namely less than $5 \%$ is characteristic for a clearly benign ganglioglioma, while an index higher than $10 \%$ is typical for an anaplastic ganglioglioma [41]. The literature features many opinions regarding a proliferative index ranging between 5\% and 10\%. Some authors believe that a Ki67\% proliferative index of $\sim 5 \%$ is fairly high for a benign neoplastic process and acknowledge that it probably should be interpreted as a $W H O$ grade II neoplasm [37, 41]. The current $W H O$ Classification reports that the mean Ki67 proliferative index should range between $1.1 \%$ and $2.7 \%$, although no range has been given for the anaplastic variant. Nonetheless, there are also authors who believe a Ki67 proliferative index of 5-7\% can be enough to establish that the lesion is indeed anaplastic [39]. Others believe that one should only diagnose a ganglioglioma if the proliferative index is less than $1 \%[45,46,51,52]$.

Another controversial immunomarker is the cluster of differentiation 34 (CD34) expression, which stains both the perikarya and the subdividing processes. The normal nervous tissue does not usually express CD34, nor do most of the central nervous system tumors (exception: pleomorphic xanthoastrocytoma). This expression, encountered in almost $80 \%$ of all gangliogliomas, is particular to this diagnosis $[37,53]$. However, this expression tends to be limited to $W H O$ grade I ganglioglioma, with most of the anaplastic gangliogliomas featuring a lack of CD34 immunoexpression [2]. This expression of the stem cell epitope might be suggestive of a malformative origin of gangliogliomas. Blümcke \& Wiestler even noticed that most of the ganglioglioma tumors which were positive for CD34 were actually located in the temporal lobe, and half of those situated in other anatomic regions lacked this expression [37]. Also, gangliogliomas with multiple dysplastic neurons, are also negative for CD34 [37]. However, the absence of this staining should not exclude the diagnosis of ganglioglioma. Majores et al. observed that grade II gangliogliomas and also glioblastoma stemming from gangliogliomas, may express CD34 only focally, in the cellular processes, giving the tumor an adverse outcome, or it may be lost altogether $[18,36]$. Intriguingly, although focal cortical dysplasia does not usually express CD34, dual lesions composed of both focal cortical dysplasia and gangliogliomas express almost invariably CD34 [37, 53].

In the literature, there are three patterns of CD34 immunostaining: the solitary pattern, where only single cells with prominent immunoreactive processes can be identified; the bushy pattern, where cells were arranged in clusters or nests, occasionally featuring satellitosis; and the diffuse pattern, which was the most frequently encountered $(55 \%)[53,54]$.

Worth mentioning for differential diagnosis is the absence of the MAP2 immunoexpression in the glial component, which differs from the usual diffuse expression seen in gliomas [2].

\section{Prognostic and therapeutic aspects}

For $W H O$ grade I gangliogliomas, surgical resection is the "gold standard". Usually, the tumor is totally resected and symptoms improve, especially the seizures [1]. A better response to therapy may be seen in younger patients, although not all studies have confirmed this hypothesis $[1,55]$. Literature data shows that after 7.5 years, patients have $97 \%$ recurrence free survival rate. Complete removal of the tumor, as well as tumors situated in the temporal lobe seems to have a better prognosis [2]. These tumors do not usually respond to radiation and some studies claim that this approach might favor a malignant transformation of the tumor [48]. This alternative should only be taken into consideration when the tumor has an unfortunate localization and the complete resection is improbable. Authors have proved that radiotherapy following subtotal surgical resection gives better local control but does not usually improve the survival rate $[56,57]$.

If the tumor was completely resected, studies have shown that the patients either seize to have any epileptic seizures $(66 \%)$, or they decrease in frequency $(33 \%)$ [58]. In rare occasions, if some residual tumor still exists, recurrences can occur, either presenting with the same HP grade, or by having a higher grade, and therefore being malignant in behavior. Some authors report cases where the recurrence happened only few months after the first intervention and the tumor featured a higher grade [48]. This data can actually endorse the idea of a three-tier grading system, but to this date, no reliable HP information predicting this outcome has been discovered.

An interesting approach of the definition of "atypical" was presented in a fairly recent study, where tumors received this label if they had an imagistic atypical aspect, i.e., which were poorly circumscribed, had a more infiltrative aspect, or an unusual location. Curiously enough, in this study, the great majority of the typical gangliogliomas were totally resected, without any adjuvant therapy, and without requiring a second surgical intervention. On the other hand, most of those interpreted as atypical, required either adjuvant chemotherapy alone, or chemotherapy combined with radiotherapy, or even a second intervention. Moreover, three of 19 cases of the clinically appearing atypical ganglioglioma, on HP examination, were either $W H O$ grade III anaplastic ganglioglioma, or had anaplastic features [59].

Majores et al. observed a higher survival rate in the WHO grade II ganglioglioma (79\%) compared to anaplastic ganglioglioma (53\%), but recurrences were noted in 33\% and malignant transformation to secondary glioblastoma in $14 \%$ of all atypical gangliogliomas, thus justifying this grading system. Interestingly, focal immunostaining 
of the cellular processes for CD34, correlated with a shorter overall survival [18]. The authors also concluded that some clinical data also influence the prognosis (male gender, age beyond 40 years, atypical localization), along with the incomplete resection and the presence of a gemistocytic component $[18,38,39]$. Other authors have observed that an unfortunate position of the tumor, and therefore an incomplete resection, correlates best with a poor outcome and did not report any correlation with the HP grade [56].

Regarding anaplastic gangliogliomas, to this moment there is insufficient data concerning the "gold standard" treatment. It is unanimously accepted that surgical removal of the entire tumor is desirable, but studies opinionate that adjuvant therapy can also be an option [38]. An argumented point of view is that of Rades et al., who has proposed the following therapeutic approach for highgrade tumors: if gross total resection was achieved, radiotherapy should not be taken into consideration, since the local control does not improve; if gross total resection was not achieved, then radiotherapy will give a better local control, but the overall survival will not improve [56]. Other study reports that a frontal location of the tumor, along with a fluid-attenuated inversion recovery (FLAIR) crossing the midline correlates with shorter overall survival. Intriguingly, they have observed that patients who have undergone subtotal resection and combined chemotherapy have a shorter progression free survival and the best overall survival was observed in cases where the tumor was totally resected, and the patient underwent adjuvant therapy with combined standard chemotherapy [60].

\section{ㅁ Conclusions}

Although no HP criteria have been established for the diagnosis of $W H O$ grade II gangliogliomas, increased cellularity, microvascular proliferation and some cellular pleomorphism have been used to define this category. Further studies concerning the immunoexpression of CD34 and Ki67 proliferation rate might offer some insight in this direction. Studies have shown that an atypical imaging aspect correlates with a higher local recurrence rate and, secondary with further reinterventions or adjuvant therapy. This aspect might have an impact on the definition of WHO grade II ganglioglioma. Regarding the therapy, it is desirable to achieve complete gross resection, in both low- and high-grade tumors, but if this goal cannot be achieved, due to an unfortunate tumor localization, then adjuvant radiotherapy can be taken into consideration. Since there have been many reports of a malignant transformation of a grade I ganglioglioma, it is imperiously necessary to follow-up the patient closely.

\section{Conflict of interests}

The authors declare that they have no conflict of interests.

\section{References}

[1] Hayat MA (ed). Tumors of the central nervous system. Volume 5 : Astrocytomas, hemangioblastomas, and gangliogliomas. Springer Science+Business Media, Dordrecht-Heidelberg-London-New York, 2012. https://doi.org/10.1007/978-94-007-2019-0
[2] Louis DN, Ohgaki H, Wiestler OD, Cavenee WK, Ellison DW, Figarella-Branger D, Perry A, Reifenberger G, von Deimling A (eds). World Health Organization (WHO) Classification of tumours of the central nervous system. $4^{\text {th }}$ edition, International Agency for Research on Cancer (IARC) Press, Lyon, France, 2016. https://publications.iarc.fr/Book-And-Report-Series/Who-Classi fication-Of-Tumours/WHO-Classification-Of-Tumours-Of-TheCentral-Nervous-System-2016

[3] Lisievici AC, Georgescu TA, Pasov D, Tascu A, Lisievici MG, Sajin M. Grading gangliogliomas: a short case series with clinico-imagistic and immunohistopathological correlations. Maedica (Bucharest), 2018, 13(3):241-249. https://doi.org/ 10.26574/maedica.2018.13.3.241 PMID: 30568746 PMCID: PMC6290183

[4] Bohiltea RE, Turcan G, Cirstoiu MM, lonescu C, Nemescu D, Turcan N, Vladareanu R. Clinical implementation of ultrasound gynecological examination report (software REGU) based on International Consensuses of Tumor Study Groups. In: Vlădăreanu S, Mărginean C, Vlădăreanu R (eds). Proceedings of the $5^{\text {th }}$ Romanian Congress of the Romanian Society of Ultrasound in Obstetrics and Gynecology, April 20-22, 2017, Târgu Mureş, Romania. Filodiritto Publisher, Bologna, Italy, 2017, 99-104. https://www.filodiritto.com/proceedings?field_ cat_proceedings_target_id=All\&page $=4$

[5] Russell DS, Rubinstein LJ. Ganglioglioma: a case with long history and malignant evolution. J Neuropathol Exp Neurol, 1962, 21(2):185-193. https://doi.org/10.1097/00005072-1962 04000-00002 PMID: 14495410

[6] Kalyan-Raman UP, Olivero WC. Ganglioglioma: a correlative clinicopathological and radiological study of ten surgically treated cases with follow-up. Neurosurgery, 1987, 20(3):428433. https://doi.org/10.1227/00006123-198703000-00012 PMID: 3574619

[7] Jay V, Squire J, Becker LE, Humphreys R. Malignant transformation in a ganglioglioma with anaplastic neuronal and astrocytic components. Report of a case with flow cytometric and cytogenetic analysis. Cancer, 1994, 73(11):2862-2868. https://doi.org/10.1002/1097-0142(19940601)73:11<2862:: aid-cncr2820731133>3.0.co;2-5 PMID: 8194028

[8] Sasaki A, Hirato J, Nakazato Y, Tamura M, Kadowaki H. Recurrent anaplastic ganglioglioma: pathological characterization of tumor cells. Case report. J Neurosurg, 1996, 84(6):10551059. https://doi.org/10.3171/jns.1996.84.6.1055 PMID: 8847572

[9] Kurian NI, Nair S, Radhakrishnan VV. Anaplastic ganglioglioma: case report and review of the literature. Br J Neurosurg, 1998, 12(3):277-280. https://doi.org/10.1080/02688699845159 PMID: 11013696

[10] Rumana CS, Valadka AB. Radiation therapy and malignant degeneration of benign supratentorial gangliogliomas. Neurosurgery, 1998, 42(5):1038-1043. https://doi.org/10.1097/000 06123-199805000-00049 PMID: 9588548

[11] Mittler MA, Walters BC, Fried AH, Sotomayor EA, Stopa EG. Malignant glial tumor arising from the site of a previous hamartoma/ganglioglioma: coincidence or malignant transformation? Pediatr Neurosurg, 1999, 30(3):132-134. https:// doi.org/10.1159/000028780 PMID: 10352415

[12] David KM, de Sanctis S, Lewis PD, Noury AMS, Edwards JMR. Neuroblastomatous recurrence of ganglioglioma. Case report. J Neurosurg, 2000, 93(4):698-700. https://doi.org/10.3171/ jns.2000.93.4.0698 PMID: 11014552

[13] Hayashi $Y$, Iwato M, Hasegawa M, Tachibana O, von Deimling A, Yamashita J. Malignant transformation of a gangliocytoma/ganglioglioma into a glioblastoma multiforme: a molecular genetic analysis. Case report. J Neurosurg, 2001, 95(1):138-142. https://doi.org/10.3171/jns.2001.95.1.0138 PMID: 11453385

[14] Wharton SB, Lammie GA, Collie DA, Whittle IR. The significance of intratumoural neurones and neuronal differentiation in diffuse gliomas: a case series. Acta Neuropathol, 2000, 100(6):695700. https://doi.org/10.1007/s004010000241 PMID: 11078222

[15] Whittle IR, Mitchener A, Atkinson HD, Wharton SB. Anaplastic progression in low grade glioneural neoplasms. Acta Neuropathol, 2002, 104(2):215. https://doi.org/10.1007/s00401-00 2-0580-2 PMID: 12212544

[16] Tarnaris A, O'Brien C, Redfern RM. Ganglioglioma with anaplastic recurrence of the neuronal element following radiotherapy. Clin Neurol Neurosurg, 2006, 108(8):761-767. https://doi.org/10.1016/j.clineuro.2005.09.005 PMID: 16219416 
[17] Mittelbronn M, Schittenhelm J, Lemke D, Ritz R, Nägele T, Weller M, Meyermann R, Beschorner R. Low grade ganglioglioma rapidly progressing to a WHO grade IV tumor showing malignant transformation in both astroglial and neuronal cell components. Neuropathology, 2007, 27(5):463-467. https:// doi.org/10.1111/j.1440-1789.2007.00800.x PMID: 18018481

[18] Majores M, von Lehe M, Fassunke J, Schramm J, Becker AJ, Simon M. Tumor recurrence and malignant progression of gangliogliomas. Cancer, 2008, 113(12):3355-3363. https:// doi.org/10.1002/cncr.23965 PMID: 18988291

[19] Reis F, Vieira GHA, Schwingel R, Gonçalves VT, Queiroz L de S. Ganglioglioma with anaplastic transformation. Arq Neuropsiquiatr, 2012, 70(9):746-747. https://doi.org/10.1590/ S0004-282X2012000900020 PMID: 22990737

[20] Lee CC, Wang WH, Lin CF, Chen HH, Chen SC, Lin SC Hung SC, Guo WY, Ho DMT, Shih YH, Hsu SPC. Malignant transformation of supratentorial ganglioglioma. Clin Neurol Neurosurg, 2012, 114(10):1338-1342. https://doi.org/10.1016/ j.clineuro.2012.03.018 PMID: 22475883

[21] Bendersky D, Tedesco N, Christiansen S, García MC, Ciraolo C. Epilepsy due to a temporal ganglioglioma and its subsequent malignant transformation into a primitive neuroectodermal tumor. Surg Neurol Int, 2012, 3:79. https://doi.org/10.4103/21527806.98511 PMID: 22937479 PMCID: PMC3424680

[22] Morana G, Piccardo A, Garrè ML, Nozza P, Consales A, Rossi A. Multimodal magnetic resonance imaging and ${ }^{18} \mathrm{~F}-\mathrm{L}$ dihydroxyphenylalanine positron emission tomography in early characterization of pseudoresponse and nonenhancing tumor progression in a pediatric patient with malignant transformation of ganglioglioma treated with bevacizumab. J Clin Oncol, 2013, 31(1):e1-e5. https://doi.org/10.1200/JCO.2012.43.6113 PMID: 23169514

[23] Zanello M, Pages M, Tauziède-Espariat A, Saffroy R, Puget $S$, Lacroix L, Dezamis E, Devaux B, Chrétien F, Andreiuolo F, Sainte-Rose C, Zerah M, Dhermain F, Dumont S, Louvel G, Meder JF, Grill J, Dufour C, Pallud J, Varlet P. Clinical, imaging, histopathological and molecular characterization of anaplastic ganglioglioma. J Neuropathol Exp Neurol, 2016 75(10):971-980. https://doi.org/10.1093/jnen/nlw074 PMID: 27539475

[24] Joyon N, Tauziède-Espariat A, Alentorn A, Giry M, Castel D, Capelle L, Zanello M, Varlet P, Bielle F. K27M mutation in $H 3 F 3 A$ in ganglioglioma grade I with spontaneous malignant transformation extends the histopathological spectrum of the histone H3 oncogenic pathway. Neuropathol Appl Neurobiol, 2017, 43(3):271-276. https://doi.org/10.1111/nan.12329 PMID: 27219822

[25] Lummus SC, Aisner DL, Sams SB, Foreman NK, Lillehei KO, Kleinschmidt-DeMasters BK. Massive dissemination from spinal cord gangliogliomas negative for BRAF V600E: report of two rare adult cases. Am J Clin Pathol, 2014, 142(2):254-260. https://doi.org/10.1309/AJCPIBSV67UVJRQV PMID: 25015869 PMCID: PMC4616006

[26] Qiu L, Tang YL, King NKK, Chuah KL, Lai SH, Lim KHC, Ng WH, Low SYY. IDH1 mutant negative ganglioglioma progression to gliosarcoma. Interdiscip Neurosurg, 2017, 9:41-44. https:// doi.org/10.1016/j.inat.2017.02.005

[27] Rosselló A, Plans G, Vidal-Sarró N, Fernández-Coello A Gabarrós A. Ganglioglioma progression to combined anaplastic ganglioglioma and anaplastic pleomorphic xanthoastrocytoma. Case report and literature review. World Neurosurg, 2017 108:996.e17-996.e25. https://doi.org/10.1016/j.wneu.2017.09. 072 PMID: 28939541

[28] Riesberg G, Bathla G, Gupta S, Watal P, Moritani T. Malignant transformation and leptomeningeal spread of recurrent ganglioglioma: case report and review of literature. Clin Imaging, 2018, 48:7-11. https://doi.org/10.1016/j.clinimag.2017.09.011 PMID: 28950177

[29] Zorlu F, Selek U, Onal C, Söylemezoğlu F, Gurkaynak M. Postoperative radiotherapy in cranial ganglioglioma. J Neurooncol, 2006, 77(3):321-324. https://doi.org/10.1007/s11060005-9050-8 PMID: 16314944

[30] Gopalakrishnan CV, Shrivastava A, Nair S, Radhakrishnan N Brainstem ganglioglioma in an infant: case report and review of literature. J Pediatr Neurosci, 2013, 8(1):41-45. https:// doi.org/10.4103/1817-1745.111422 PMID: 23772244 PMCID: PMC3680895

[31] Pikis S, Petrosyan T, Diamantopoulou K, Kelesis C. Anaplastic ganglioglioma becoming symptomatic in the third trimester of pregnancy. Int J Reprod Contracept Obstet Gynecol, 2017, 6(3):1158-1160. https://doi.org/10.18203/2320-1770.jircog2017 0608

[32] Munteanu O, Voicu D, Voiculescu DI, Negreanu L, Georgescu TA, Sajin M, Berceanu C, Mehedinţu C, Brătilă E, Istrate-Ofiţeru AM, Cîrstoiu MM. Colon cancer in pregnancy: a diagnostic and therapeutic challenge. Rom J Morphol Embryol, 2019, 60(1): 307-317. PMID: 31263861

[33] Lang FF, Epstein FJ, Ransohoff J, Allen JC, Wisoff J, Abbott IR, Miller DC. Central nervous system gangliogliomas. Part 2: Clinical outcome. J Neurosurg, 1993, 79(6):867-873. https:// doi.org/10.3171/jns.1993.79.6.0867 PMID: 8246055

[34] Higa N, Yonezawa H, Oyoshi T, Hiraki T, Hirano H, Arita K. Ganglioglioma in the third ventricle: a case report and literature review. NMC Case Rep J, 2016, 3(3):97-101. https://doi.org/ 10.2176/nmccrj.cr.2016-0038 PMID: 28664007 PMCID: PMC 5386175

[35] Oppenheimer DC, Johnson MD, Judkins AR. Ganglioglioma of the spinal cord. J Clin Imaging Sci, 2015, 5:53. https:// doi.org/10.4103/2156-7514.166355 PMID: 26605127 PMCID: PMC4629305

[36] Čupić H, Sajko T, Sesar N, Ivica M, Pažanin L. Malignant transformation of grade II ganglioglioma to glioblastoma: a case report. Transl Neurosci, 2012, 3(2):213-216. https://doi.org/ 10.2478/s13380-012-0017-x

[37] Blümcke I, Wiestler OD. Gangliogliomas: an intriguing tumor entity associated with focal epilepsies. J Neuropathol Exp Neurol, 2002, 61(7):575-584. https://doi.org/10.1093/jnen/61. 7.575 PMID: 12125736

[38] Kang DH, Lee CH, Hwang SH, Park IS, Han JW, Jung JM. Anaplastic ganglioglioma in a middle-aged woman: a case report with a review of the literature. J Korean Med Sci, 2007, 22(Suppl):S139-S144. https://doi.org/10.3346/jkms.2007.22. S.S139 PMID: 17923741 PMCID: PMC2694381

[39] Lucas JT Jr, Huang AJ, Mott RT, Lesser GJ, Tatter SB, Chan MD. Anaplastic ganglioglioma: a report of three cases and review of the literature. J Neurooncol, 2015, 123(1):171-177. https:// doi.org/10.1007/s11060-015-1781-6 PMID: 25862009 PMCID: PMC4471868

[40] Nair V, Suri VS, Tatke M, Saran RK, Malhotra V, Singh D. Gangliogliomas: a report of five cases. Indian J Cancer, 2004, 41(1):41-46. PMID: 15105579

[41] Tonn JC, Westphal M, Rutka JT, Grossman SA (eds). Neurooncology of CNS tumors. Springer-Verlag, Berlin-HeidelbergNew York, 2006. https://doi.org/10.1007/3-540-31260-9

[42] Provenzale JM, Ali U, Barboriak DP, Kallmes DF, Delong DM, McLendon RE. Comparison of patient age with MR imaging features of gangliogliomas. Am J Roentgenol, 2000, 174(3): 859-862. https://doi.org/10.2214/ajr.174.3.1740859 PMID: 10701639

[43] Gelabert-González M, Santín Amo JM, Arcos Algaba A, Serramito García R, Castro Bouzas D, Díaz Cabana L, Prieto González A, Aran Echabe E, Bandín Diéguez FJ, Villa Fernández J, García Allut A. [Intracranial gangliogliomas. A review of a series of 20 patients]. Neurologia, 2011, 26(7): 405-415. https://doi.org/10.1016/j.nrl.2010.09.014 PMID: 21163217

[44] Mei PA, Gonçalves VT, Bertanha R, Reis F. Gangliogliomas: a retrospective study about magnetic resonance imaging in a series of cases with histopathological confirmation. J Neurol Sci, 2015, 357(Suppl 1):e225. https://doi.org/10.1016/j.jns.2015. 08.778

[45] Odia Y. Gangliocytomas and gangliogliomas: review of clinical, pathologic and genetic features. Clin Oncol, 2016, 1(1):1017. https://www.clinicsinoncology.com/full-text/cio-v1-id1017.php

[46] Hirose T, Scheithauer BW, Lopes MBS, Gerber HA, Altermatt HJ, VandenBerg SR. Ganglioma: an ultrastructural and immunohistochemical study. Cancer, 1997, 79(5):989-1003. https:// doi.org/10.1002/(SICI)1097-0142(19970301)79:5<989::AIDCNCR16>3.0.CO;2-Z PMID: 9041162

[47] Jaffey PB, Mundt AJ, Baunoch DA, Armstrong DL, Hamilton WJ, Zagaja VG, Grossman RG, Wollmann RL. The clinical significance of extracellular matrix in gangliogliomas. J Neuropathol Exp Neurol, 1996, 55(12):1246-1252. https://doi.org/10.1097/ 00005072-199612000-00008 PMID: 8957448

[48] Hayat MA (ed). Tumors of the central nervous system. Volume 9 : Lymphoma, supratentorial tumors, glioneuronal tumors, gangliogliomas, neuroblastoma in adults, astrocytomas, ependymomas, 
hemangiomas, and craniopharyngiomas. Springer Science+ Business Media, Dordrecht, 2012. https://doi.org/10.1007/97894-007-5488-1

[49] Luyken C, Blümcke I, Fimmers R, Urbach H, Wiestler OD, Schramm J. Supratentorial gangliogliomas: histopathologic grading and tumor recurrence in 184 patients with a median follow-up of 8 years. Cancer, 2004, 101(1):146-155. https:// doi.org/10.1002/cncr.20332 PMID: 15222000

[50] Bouali S, Ben Said I, Zehani A, Drissi C, Bouhoula A, Kallel J, Jemel $\mathrm{H}$. Pediatric intracranial anaplastic gangliogliomas: illustrative case and systematic review. World Neurosurg, 2018, 119:220-231. https://doi.org/10.1016/j.wneu.2018.07. 278 PMID: 30098436

[51] Prayson RA, Khajavi K, Comair YG. Cortical architectura abnormalities and MIB1 immunoreactivity in gangliogliomas: a study of 60 patients with intracranial tumors. J Neuropathol Exp Neurol, 1995, 54(4):513-520. https://doi.org/10.1097/00 005072-199507000-00005 PMID: 7541447

[52] Wolf HK, Müller MB, Spänle M, Zenther J, Schramm J, Wiestler OD. Ganglioglioma: a detailed histopathological and immunohistochemical analysis of 61 cases. Acta Neuropathol, 1994, 88(2):166-173. https://doi.org/10.1007/BF00294510 PMID: 7985497

[53] Deb P, Sharma MC, Tripathi M, Sarat Chandra P, Gupta A, Sarkar C. Expression of CD34 as a novel marker for glioneuronal lesions associated with chronic intractable epilepsy. Neuropathol Appl Neurobiol, 2006, 32(5):461-468. https:// doi.org/10.1111/j.1365-2990.2006.00734.x PMID: 16972880

[54] Blümcke I, Löbach M, Wolf HK, Wiestler OD. Evidence for developmental precursor lesions in epilepsy-associated glioneuronal tumors. Microsc Res Tech, 1999, 46(1):53-58. https:// doi.org/10.1002/(SICI)1097-0029(19990701)46:1<53::AIDJEMT5>3.0.CO;2-0 PMID: 10402272

[55] Ogiwara H, Nordli DR, DiPatri AJ, Alden TD, Bowman RM, Tomita T. Pediatric epileptogenic gangliogliomas: seizure outcome and surgical results - clinical article. J Neurosurg Pediatr, 2010, 5(3):271-276. https://doi.org/10.3171/2009.10.PEDS09372 PMID: 20192644
[56] Rades D, Zwick L, Leppert J, Bonsanto MM, Tronnier V, Dunst J, Schild SE. The role of postoperative radiotherapy for the treatment of gangliogliomas. Cancer, 2010, 116(2):432-442. https://doi.org/10.1002/cncr.24716 PMID: 19908258

[57] Liauw SL, Byer JE, Yachnis AT, Amdur RJ, Mendenhall WM. Radiotherapy after subtotally resected or recurrent ganglioglioma. Int J Radiat Oncol Biol Phys, 2007, 67(1):244-247. https://doi.org/10.1016/j.jrobp.2006.08.029 PMID: 17045420

[58] Giulioni M, Rubboli G, Marucci G, Martinoni M, Volpi L, Michelucci R, Marliani AF, Bisulli F, Tinuper P, Castana L, Sartori I, Calbucci F. Seizure outcome of epilepsy surgery in focal epilepsies associated with temporomesial glioneuronal tumors: lesionectomy compared with tailored resection - clinical article. J Neurosurg, 2009, 111(6):1275-1282. https://doi.org/ 10.3171/2009.3.JNS081350 PMID: 19408976

[59] Patibandla MR, Ridder T, Dorris K, Torok MR, Liu AK, Handler MH, Stence NV, Fenton LZ, Hankinson TC. Atypical pediatric ganglioglioma is common and associated with a less favorable clinical course. J Neurosurg Pediatr, 2016, 17(1): 41-48. https://doi.org/10.3171/2015.6.PEDS15215 PMID: 26431248

[60] Terrier LM, Bauchet L, Rigau V, Amelot A, Zouaoui S, Filipiak I, Caille A, Almairac F, Aubriot-Lorton MH, Bergemer-Fouquet AM, Bord E, Cornu P, Czorny A, Dam Hieu PD, Debono B, Delisle MB, Emery E, Farah W, Gauchotte G, Godfraind C, Guyotat J, Irthum B, Janot K, Le Reste PJ, Liguoro D, Loiseau H, Lot G, Lubrano V, Mandonnet $E$, Menei $P$, Metellus $P$, Milin $S$, Muckenstrum B, Roche PH, Rousseau A, Uro-Coste E, Vital A, Voirin J, Wager M, Zanello M, François $P$, Velut $S$, Varlet $P$, Figarella-Branger D, Pallud J, Zemmoura I; Club de NeuroOncologie of the Société Française de Neurochirurgie. Natural course and prognosis of anaplastic gangliogliomas: a multicenter retrospective study of 43 cases from the French Brain Tumor Database. Neuro Oncol, 2017, 19(5):678-688. https:// doi.org/10.1093/neuonc/now186 PMID: 28453747 PMCID: PMC5464461

\section{Corresponding authors}

Tiberiu Augustin Georgescu, Assistant Professor, MD, PhD, Discipline of Pathology, Carol Davila University of Medicine and Pharmacy, 8 Eroilor Sanitari Avenue, Sector 5, 050474 Bucharest, Romania; Phone +40721-468 622, e-mail: tiberiuaugustin.georgescu@gmail.com

Roxana Elena Bohîltyea, Associate Professor, MD, PhD, Discipline of Obstetrics and Gynecology, Carol Davila University of Medicine and Pharmacy, 8 Eroilor Sanitari Avenue, Sector 5, 050474 Bucharest, Romania; Phone +40722-383 060, e-mail: r.bohiltea@yahoo.com

Received: March 11, 2021

Accepted: November 17, 2021 